\title{
Consultoria colaborativa: estratégias para o ensino de leitura e escrita ${ }^{1}$
}

\section{Priscila Benitez ${ }^{2}$ \\ Camila Domeniconi}

Universidade Federal de São Carlos, São Carlos - SP - Brasil

\begin{abstract}
Resumo: A consultoria colaborativa, a partir do trabalho do psicólogo escolar, pode auxiliar os professores na programação do ensino de habilidades básicas de leitura e escrita para estudantes com deficiência intelectual (DI) e transtorno do espectro autista (TEA). O objetivo geral desse estudo foi avaliar a eficácia de uma consultoria colaborativa oferecida pelo psicólogo escolar em duas situações educacionais: uma aplicada pelo professor da sala de aula (PSA) comum com todos os estudantes (Experimento I) e, a outra, aplicada pelo professor de educação especial (PEE), de modo individualizado (Experimento 2). Após as intervenções, os desempenhos médios de leitura e escrita para a intervenção aplicada pelo professor de sala foram $86 \%$ e $83 \%$ de acertos e na intervenção pelo professor de educação especial 78\% e 65\%. A atuação do psicólogo na estruturação das intervenções e no acompanhamento detalhado dos desempenhos demonstrou uma possibilidade de trabalho como consultor colaborativo.
\end{abstract}

Palavras-chave: consultoria colaborativa; escrita; inclusão escolar; leitura; professores.

\section{COLLABORATIVE CONSULTING: STRATEGIES FOR READING AND WRITING TEACHING}

\begin{abstract}
The collaborative consulting, from the school psychologist work, can assist teachers in planning teaching basic reading and writing skills for learners with intellectual disabilities (ID) and autism spectrum disorder (ASD). The general objective of this study was to evaluate the effectiveness of a collaborative consultation offered by the school psychologist in two educational situations: an applied by the teacher in the classroom with all students (Experiment I) and; the other applied by the special education teacher, individualized mode (Experiment 2). After interventions, the average performance in reading and writing to the intervention applied by class teacher were $86 \%$ and $83 \%$ correct answers and intervention by the special education teacher $78 \%$ and $65 \%$. The role of the psychologist in the structuring of interventions and detailed monitoring demonstrated a possibility of collaborative work as consultant.
\end{abstract}

Keywords: collaborative consultation; writing; school inclusion; reading; teachers.

1 Este trabalho recebeu financiamento da bolsa de estudos de doutorado, referente à primeira autora, concedido pela Fundação de Amparo à Pesquisa do Estado de São Paulo - Fapesp (Processo n. 2010/16701-0). Ele pertence ao programa do Instituto Nacional de Ciência e Tecnologia sobre Comportamento, Cognição e Ensino (coordenado por Deisy G. de Souza), financiado pelo Conselho Nacional de Desenvolvimento Científico e Tecnológico - CNPq (\# 573972/2008-7) e Fapesp (\#2008/ 57705-8).

2 Endereço para correspondência: Priscila Benitez, Universidade Federal de São Carlos, Rua do Agronegócios, 184, São Carlos - SP - Brasil. CEP: 13566-423. E-mail: pribenitez@yahoo.com.br. 


\begin{abstract}
Resumen: La consultoría de colaboración, a partir del trabajo del psicólogo de la escuela, puede ayudar a los profesores en la planificación de la enseñanza de las habilidades básicas de lectura y escritura para los alumnos con discapacidad intelectual (DI) y trastorno del espectro autista (TEA). El objetivo general de este estudio fue evaluar la eficacia de uno asesoramiento de colaboración ofrecida por el psicólogo de la escuela en dos situaciones educativas: un aplicado por el profesor en el aula con todos los estudiantes (Experimento I) y otro aplicado por el maestro de educación especial, de modo individualizado (Experimento 2). Después de las intervenciones, el rendimiento promedio en la lectura y la escritura a la intervención aplicada por el maestro del aula fue $86 \%$ y el $83 \%$ de respuestas correctas y la intervención por parte del maestro de educación especial del $78 \%$ y $65 \%$. El papel del psicólogo en la estructuración de las intervenciones y el desempeño detallado monitoreo demostró una posibilidad de trabajo colaborativo como consultor.
\end{abstract}

Palabras clave: consultoría de colaboración; escritura; inclusión escolar; lectura; maestros.

A garantia da participação efetiva dos estudantes nas atividades da sala de aula comum, especialmente com dificuldades de origem cognitiva (como deficiência intelectual DI) e sociais (como o transtorno do espectro autista - TEA), tem gerado discussões sobre ajustes e reflexões das práticas pedagógicas adotadas nos espaços escolares (públicos e privados) nacionais (Araujo \& Almeida, 2014; Rodrigues, Moreira, \& Lerner, 2012). A normativa oficial (Brasil, 2013 ) ainda carece de uma melhor operacionalização, para que seja possível padronizar em todos os sistemas de ensino (públicos ou privados) as mesmas condições de promoção de aprendizagem para todos os estudantes.

A DI apresenta limitações no funcionamento cognitivo e nas habilidades adaptativas que envolvem as habilidades conceituais, sociais e práticas. No tocante às limitações nas habilidades sociais, o TEA envolve déficits mais específicos na interação social (como, interesses restritos e comportamentos estereotipados), déficits sociocomunicativos e, em alguns casos, tais déficits também se encontram no funcionamento cognitivo. A definição do TEA pelos manuais oficiais envolve uma classe de condições neurodesenvolvimentais que acometem a qualidade e a sequência do desenvolvimento. $A$ soma de tais déficits limita a qualidade de vida do estudante com TEA e o funcionamento em atividades diárias (APA, 2013 ; Fein et al., 2013; Zanon, Backes \& Bosa, 2014).

A participação efetiva dos estudantes com DI e TEA na sala comum requer o serviço de outros profissionais que sejam responsáveis pela adaptação das atividades em sala de aula, realização da atividade conjunta com o estudante, minimização dos comportamentos destrutivos, adequação quando necessária da estratégia para a promoção da aprendizagem pedagógica e não apenas social. Esses profissionais são identificados e descritos na literatura com diferentes nomes, nos estudos norte-americanos: paraprofessional (Leblanc, Ricciardi, \& Luiselli, 2005), nos trabalhos ingleses: key-worker (Webb, Greco, Sloper, \& Beecham, 2008), nas pesquisas gregas: shadowteacher (Gena, 2006) e nos trabalhos brasileiros: educadores especiais (ou professores de educação especial), acompanhantes terapêuticos, ou ainda tutores/facilitadores (Benitez \& Domeniconi, 2014). 
Uma proposta que direciona a atuação e a interação entre esses dois professores (da sala e da educação especial), de modo a favorecer a efetiva participação do aluno com DI e TEA nas atividades acadêmicas, se dá a partir da colaboração entre professores, pais e demais profissionais. Esta colaboração pode ocorrer em dois formatos: ensino colaborativo ou coensino e consultoria colaborativa. No modelo do coensino, o professor de educação especial e da sala de aula comum compartilham a responsabilidade de planejar, aplicar e avaliar os estudantes. Na proposta de consultoria colaborativa, o professor de educação especial proporciona auxílio ao professor de ensino regular fora da sala de aula e pode envolver outros profissionais, em geral, abarcando o consultor, a equipe escolar, podendo estender até a família, a comunidade e demais profissionais adicionais (Araújo \& Almeida, 2014; Mendes, Almeida, \& Toyoda, 2011; Rosin-Pinola, \& Del Prette, 2014; Silva \& Mendes, 2012).

Essas duas propostas de atuação entre o professor de educação especial e o da sala comum servem como importantes recursos para a inclusão escolar, a fim de estabelecer práticas pedagógicas concretas de parceria, dentro ou fora da sala de aula, em prol da efetivação da inclusão escolar (Araújo \& Almeida, 2014; Rosin-Pinola \& Del Prette, 2014).

Vilaronga e Mendes (2014) relataram práticas de ensino colaborativo com professores de educação especial que tinham participado de um curso de formação sobre o tema. Quatro professores relataram suas práticas colaborativas desenvolvidas em parceria com o professor da sala de aula comum, e como tais atividades adaptadas para a necessidade do aluno público-alvo da educação especial favoreceram a participação efetiva nas atividades escolares. Como uma conquista política do estudo, a proposta de ensino colaborativo no município de São Carlos-SP que ainda não integrava o Plano Municipal de Educação. Após a realização desse trabalho, passou a compor tal Plano para os próximos 10 anos.

Mendes et al. (2011), por sua vez, aplicaram uma consultoria colaborativa e relataram um histórico sobre um programa de pesquisa, ensino e extensão que envolveu desde alunos de graduação até professores do ensino comum, com início em 2004, na Universidade Federal de São Carlos. Esse programa teve como propósito a formação inicial dos estudantes de graduação e a formação continuada dos professores para a elaboração de estratégias que promovessem o trabalho colaborativo no espaço escolar. A busca pelo programa de formação nos anos posteriores demonstrou a adesão dos professores para implementar na sala de aula esse modelo de ensino.

Nesses dois modelos de ensino, o professor da sala de aula comum e o professor de educação especial necessitam, portanto, de um trabalho em conjunto durante o planejamento e de capacitações que garantam a elaboração de atividades que visem o desenvolvimento das habilidades sociais dos estudantes, tais como acadêmicas, com destaque a leitura e a escrita, por serem a base para toda a aprendizagem acadêmica posterior (Araújo \& Almeida, 2014; Sanches \& Oliveira, 2011; Vilaronga \& Mendes, 2014).

Em termos de avaliação de desempenho acadêmico desse alunado em provas de larga escala que servem como indicador da qualidade do sistema educacional nacional, 
como a Prova Brasil (composta por testes de língua portuguesa e de matemática), um estudo paranaense identificou participação mínima nessa avaliação, o que sustenta a análise de não incentivo e não participação nestas provas devido às questões financeiras envolvidas nos resultados delas, como o financiamento da educação e o repasse de verbas às escolas. Além disso, a maioria desses estudantes estava matriculada nos anos iniciais do ensino fundamental, o que pode significar a não progressão para as etapas de ensino posteriores (Meletti \& Bueno, 2011; Silva \& Meletti, 2014).

Os dados do Censo do Instituto Brasileiro de Geografia e Estatística (IBGE) do ano de 2010, publicados pela prefeitura do município de São Paulo, em relação ao número de crianças com diagnóstico DI matriculadas nas escolas comuns no estado de São Paulo, indicaram que, de 22.763 crianças entre cinco e nove anos, 16.038 ainda não estão alfabetizadas. Isso significa que $70 \%$ dessas crianças não aprenderam a ler e a escrever nos anos iniciais do ensino fundamental.

A inclusão escolar do estudante com DI (o que também se aplica àqueles com TEA) envolve um trabalho social e acadêmico. No tocante ao trabalho acadêmico, a sistematização de uma proposta de ensino das habilidades básicas necessárias para ler e escrever ainda se revela como um desafio para muitos professores. Desafios estes que são oriundos de diferentes áreas (de ordem cognitiva, bem como o déficit de habilidades sociais e, em alguns casos, a presença de comportamentos desafiadores e destrutivos). Estes desafios podem ser superados com a presença de uma equipe multidisciplinar, a partir do envolvimento de outros profissionais, como a atuação do psicólogo escolar (como consultor) em parceria com ambos os professores. A consultoria colaborativa pode contribuir na busca de atividades e formas de avaliação em conjunto com ambos os professores que vislumbrem o ensino de leitura e escrita para estudantes com DI e TEA (Araújo \& Almeida, 2014; Silva \& Mendes, 2012).

O psicólogo escolar como consultor pode contribuir não apenas na prevenção e redução dos problemas de comportamentos de estudantes com DI e TEA, como pode, sobretudo, contribuir no planejamento e programação de ensino detalhada de atividades ou, ainda, na estruturação e organização de intervenções de ensino, a partir dos trabalhos que já são desenvolvidos pelos professores em seus ambientes naturais de ensino. Os dados de Silva e Mendes (2012) mostraram o papel do psicólogo escolar na consultoria colaborativa em parceria com os professores, com o objetivo de prevenir e reduzir problemas de comportamento. O programa conduzido com os professores e com os estudantes envolveu discussões, teorias e visitas nas salas de aula. Os resultados demonstraram a importância do trabalho desse profissional nesse âmbito da consultoria colaborativa com os professores.

Os conhecimentos produzidos pela Psicologia contribuem para o planejamento e sistematização de atividades típicas do cotidiano escolar desses professores, a partir do emprego de medidas avaliativas constantes, com o propósito de verificar os progressos dos estudantes. Tal consultoria pode contribuir não apenas no âmbito da remediação, ou seja, na resolução de dificuldades presentes no espaço escolar, mas tam- 
bém na prevenção destas dificuldades (Araújo \& Almeida, 2014; Silva \& Mendes, 2012). Uma forma de garantir a consultoria colaborativa com os professores da sala de aula e da educação especial pode ser por meio de objetivos de ensino similares, mas em contextos e procedimentos de ensino diferenciados, com a presença de outros profissionais, como o psicólogo escolar

O objetivo geral desse estudo foi avaliar a eficácia de uma consultoria colaborativa oferecida pelo psicólogo escolar em duas situações educacionais: uma aplicada pelo professor da sala de aula (PSA) comum com todos os estudantes (Experimento 1) e, a outra, aplicada pelo professor de educação especial (PEE), de modo individualizado (Experimento 2). O Experimento 1 teve como objetivo avaliar a aprendizagem de leitura e escrita de estudantes com DI e TEA em uma intervenção aplicada pelo PSA. O Experimento 2 teve como finalidade avaliar a aprendizagem de leitura e escrita de estudantes com DI e TEA em uma intervenção aplicada pelo PEE, de maneira individualizada, durante o AEE.

\section{Método}

\section{Experimento I}

\section{Participantes}

\section{Tabela I. Caracterização das duplas participantes}

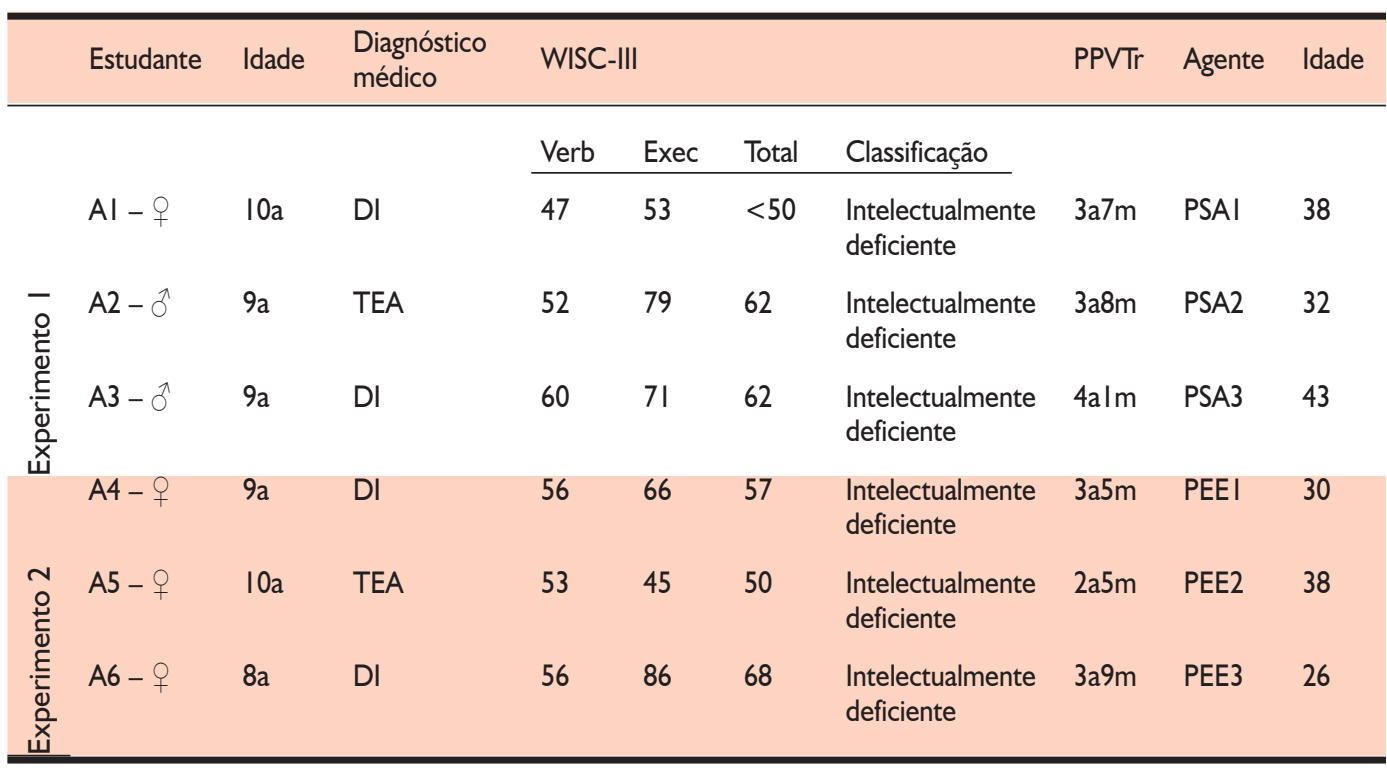

Fonte: Elaborado pelos autores.

Nota: WISC-III refere-se a Wechsler Intelligence Scala e for Children (Wechsler \& Figueiredo, 2002) e investiga as diversas habilidades cognitivas que contemplam a capacidade intelectual geral do indivíduo. PPVTr refere-se ao teste Peabody Picture Vocabulary Test, o qual fornece a idade da criança equivalente ao vocabulário. PS refere-se ao professor da sala e PEE ao professor da Educação Especial. 
Os participantes foram compostos por três duplas de professores de sala e estudantes (PS1-A1, PS2-A2, PS3-A3). As principais características desses participantes estão apresentadas na Tabela 1.

\section{Situação e materiais}

A coleta de dados ocorreu em três salas de aulas. Cada sessão teve duração aproximada de 30 minutos e foi aplicada, em geral, três vezes por semana. Foi utilizada uma filmadora para registrar uma amostra de $30 \%$ de cada sessão.

Os materiais utilizados para aplicação da intervenção foram 14 textos elaborados pela pesquisadora. As palavras foram as mesmas utilizadas nos dois Experimentos. Os materiais foram fornecidos aos professores dos Experimentos 1 e 2, juntamente com as instruções para o uso de cada um deles.

\section{Delineamento experimental}

O delineamento adotado nos Experimentos 1 e 2 foi o de linha de base múltipla entre conjunto de palavras. O procedimento foi estruturado em três avaliações gerais (AG) repetidas. A primeira foi aplicada antes de qualquer ensino e serviu como medida de pré-teste. A segunda foi aplicada após o ensino do primeiro conjunto de palavras, composto por sete palavras com duas silabas. A terceira foi aplicada após o ensino do segundo conjunto de palavras, composto por sete palavras com três silabas e serviu como medida de pós-teste.

\section{Procedimento geral}

Fase 1: Planejamento do Experimento 1

O ensino proposto teve a mesma estrutura para os Experimentos 1 e 2 . As principais características foram: a) ensino de uma palavra por vez, b) alternância no aparecimento da palavra de ensino na frase, ora como sujeito, ora como predicado, e c) era solicitado que o estudante apontasse para a palavra de ensino-alvo. Cada ensino foi composto pelo treino de sete palavras, as quais foram ensinadas por uma única intervenção, sem alternância. O Ensino 1 foi composto pelas palavras: "fogo", "mala", "galo", "bola", "pipa", "luva", "rede". O Ensino 2 treinou: "tomate", "salada", "gaveta", "panela", "boneca", "fivela", "muleta". Lembrando que cada palavra foi ensinada em uma atividade específica que envolvia a leitura oral de um texto por cada PSA.

Nas sessões de ensino, os professores da sala de aula eram instruídos a ler em voz alta todas as frases de um livro elaborado pela pesquisadora sobre cada palavra de ensino. O material era composto por 30 frases, em que a palavra de ensino aparecia 30 vezes, uma vez em cada frase. Cada palavra alternava sua posição na frase, ora aparecia como sujeito, ora como predicado. 
Fase 2: Recrutamento das duplas (professores-estudantes)

Nesta fase, foram recrutados e selecionados três professores de sala de aula que tinham um estudante com TEA ou DI matriculado em sua sala e os três respectivos estudantes.

Fase 3: Aplicação do pré-teste (linha de base - AG1)

Todos os estudantes realizaram a AG1 que serviu para avaliar o repertório inicial de cada estudante nas tarefas de leitura e escrita.

Fase 4: Treinamento geral com os professores

Na sequência, ocorreu o treino individualizado com cada professor para apresentar o procedimento de aplicação. O objetivo desse treino foi ensiná-los a aplicar tecnicamente as sessões.

Fases 5 e 6: Aplicação das sessões e supervisão

As intervenções foram aplicadas por cada professor, em suas respectivas salas. A Fase 6 (Supervisão) ocorreu simultaneamente com a aplicação das sessões (Fase 5). Todas as avaliações foram aplicadas pela pesquisadora. Para aplicação de cada sessão eram realizadas supervisões com cada professor.

Fase 7: Aplicação do pós-teste (AG3)

Ao finalizar a aplicação dos dois Ensinos, a pesquisadora reaplicou a Avaliação Geral (AG3) como medida de pós-teste para verificar se o estudante apresentou progresso nas tarefas de leitura e escrita, com relação ao seu repertório de entrada.

\section{Análise dos dados}

A análise de dados proposta foi em relação ao desempenho dos estudantes nas três avaliações, de acordo com o delineamento proposto. As três avaliações permitiram acompanhar o progresso individual de cada estudante para as tarefas de emparelhamento palavra impressa-figura, figura-palavra impressa, nomeação de palavra impressa, ditado por composição e manuscrito. Com relação à consultoria colaborativa, a análise qualitativa dos dados previu a implementação das intervenções aplicadas pelos professores, em conformidade com o planejamento proposto para cada Experimento.

\section{Experimento 2}

\section{Participantes}

A amostra foi composta por três duplas de professores de educação especial e estudantes (PEE1-A4, PEE2-A5, PEE3-A6). As principais características desses participantes foram apresentadas na Tabela 1.

\section{Situação e materiais}

A coleta de dados ocorreu em três salas, em que os professores de Educação Especial desenvolviam seus respectivos trabalhos. Cada sessão teve duração aproximada de 
30 minutos e foi aplicada, em geral, três vezes por semana, com exceção de A5, pois a escola autorizou que A5 participasse das atividades uma vez por semana. Foi utilizada uma filmadora para registrar uma amostra de 30\% de cada sessão.

Os materiais utilizados para aplicação da intervenção foram 14 sessões informatizadas, elaboradas pela pesquisadora.

\section{Procedimento geral}

O ensino proposto no Experimento 2 apresentou as mesmas características daquelas descritas para o Experimento 1. Contudo, cada palavra que foi ensinada no Experimento 2 foi estruturada em uma atividade informatizada, aplicada pelo PEE, durante o AEE. As demais etapas do procedimento foram similares àquelas descritas para o Experimento 1.

\section{Resultados}

Os resultados aqui reunidos foram apresentados em relação ao desempenho de cada estudante nas três AG, para as tarefas de leitura (Figura 1): tarefas de emparelhamento palavra impressa-figura e figura-palavra impressa e nomeação de palavra impressa; e para as tarefas de escrita (Figura 2): ditado manuscrito e por composição.

Figura I. Desempenho dos estudantes participantes do Experimento I nas tarefas de leitura (emparelhamento figura-palavra impressa - linha cinza escuro com losango, palavra impressa-figura - linha cinza claro com triângulo e nomeação da palavra - linha cinza médio com círculo, nas três Avaliações Gerais (AGI, AG2 e AG3) e de escrita (ditado manuscrito - linha cinza escuro com losango e ditado por composição - linha cinza claro com triangulo, respectivamente) nas três Avaliações Gerais (AG I, AG2 e AG3). As linhas contínuas representam o momento em que cada ensino foi aplicado.

A1

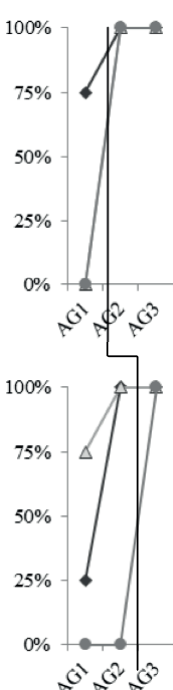

A2

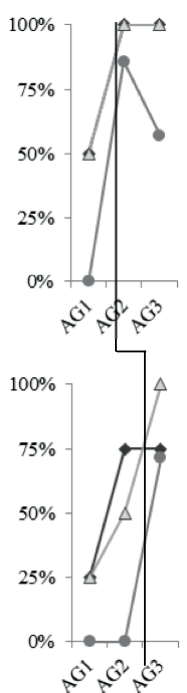

A3

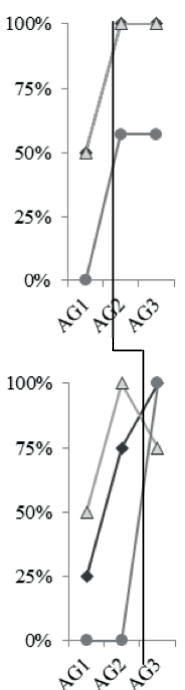

A1

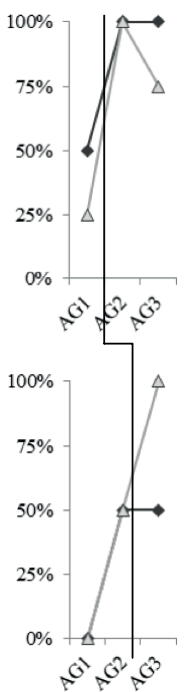

A2

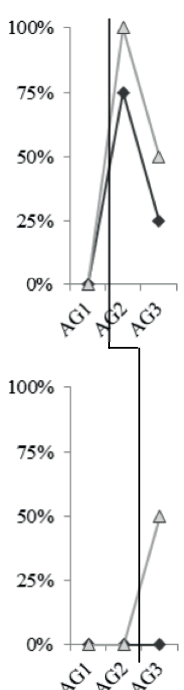

A3

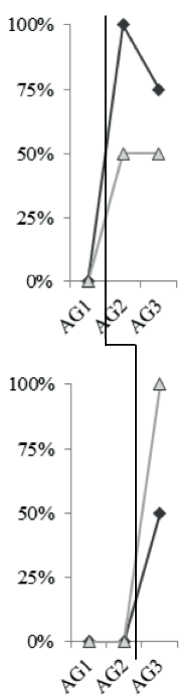

Fonte: Elaborado pelos autores. 
Figura 2. Desempenho dos estudantes participantes do Experimento 2 nas tarefas de leitura (emparelhamento figura-palavra impressa - linha cinza escuro com losango, palavra impressa-figura - linha cinza claro com triângulo e nomeação da palavra - linha cinza médio com círculo, nas três Avaliações Gerais (AGI, AG2 e AG3) e de escrita (ditado manuscrito - linha cinza escuro com losango e ditado por composição - linha cinza claro com triangulo, respectivamente) nas três Avaliações Gerais (AGI, AG2 e AG3). As linhas contínuas representam o momento em que cada ensino foi aplicado.
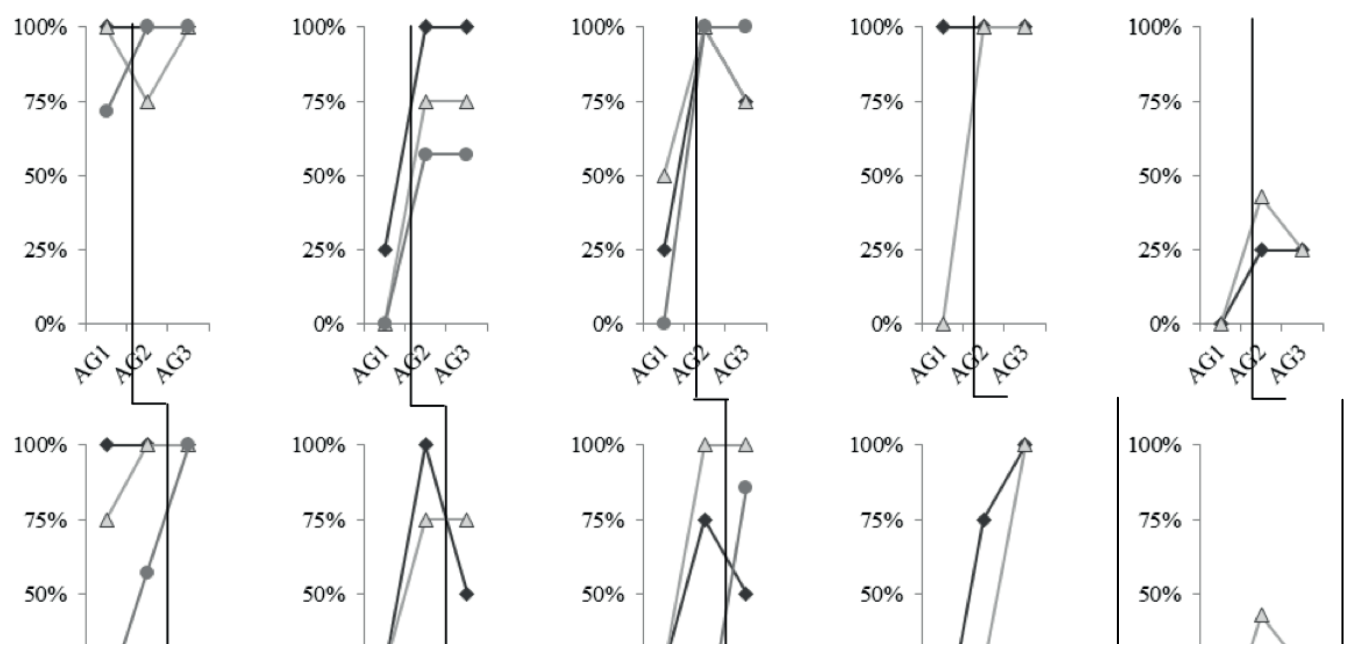

Fonte: Elaborado pelos autores.

\section{Discussão}

O presente estudo teve como objetivo geral avaliar a eficácia de uma consultoria colaborativa oferecida pelo psicólogo escolar em duas situações educacionais: uma aplicada pelo professor da sala de aula (PSA) comum com todos os estudantes (Experimento 1) e a outra aplicada pelo professor de educação especial (PEE), de modo individualizado (Experimento 2). Os achados do estudo mostram, por um lado, a efetividade da consultoria colaborativa estabelecida pelo psicólogo escolar em relação à implementação das intervenções aplicadas por cada professor em cada Experimento; e, por outro lado, os dados permitem comparar diferentes estratégias de ensino para a intervenção em leitura e escrita.

Os estudantes tinham diagnósticos médicos de DI e TEA, estavam matriculados em escolas comuns e ao serem expostos a 14 sessões de ensino (sendo uma sessão aplicada por dia, que visava o ensino de uma única palavra, com duração média de 20 minutos por dia), aprenderam a ler (figuras 1 e 2) e escrever (figuras 1 e 2) as palavras isoladas ensinadas diretamente por cada professor, a partir de um esquema de consultoria colaborativa, com o psicólogo escolar. Mesmo diante da baixa frequência de aplicação (uma vez por semana) do ensino com A5, os desempenhos (Figura 2) na AG2 foram maiores em comparação aos desempenhos na AG1. É importante identificar que tal 
frequência pode ter influenciado em alguma medida no desempenho do estudante e, principalmente, em uma análise comparativa com os demais estudantes.

As replicações sistemáticas de cada avaliação garantiram maior desempenho nas avaliações finais, quando comparadas às iniciais, tanto para leitura como para escrita. $\mathrm{Na}$ intervenção aplicada pelo professor de sala de aula, para a tarefa de nomeação de palavra, todos mostraram desempenhos nulos na AG1 (pré-teste) e após o ensino das palavras, A1 e A2 leram 79\% das palavras e A3 leu todas corretamente. Para a tarefa de ditado por composição, com exceção de $A 1$ que escreveu $25 \%$ das palavras corretamente no pré-teste (AG1) e $50 \%$ para o ditado manuscrito, os demais apresentaram desempenhos nulos. Após o ensino, A1 e A2 escreveram corretamente $75 \%$ das palavras e $A 3$ escreveu todas as palavras. Com relação à intervenção aplicada pelo professor de educação especial, com exceção de A4 que leu $43 \%$ das palavras na AG1, os demais não leram nenhuma palavra. Para a escrita sob controle de ditado manuscrito, com exceção de A4 que escreveu todas as palavras corretamente na AG1, os demais não escreveram nenhuma palavra. E, na tarefa de ditado por composição, todos apresentaram desempenho nulo na AG1. Após o ensino A4, A5 e A6 demonstraram $93 \%$ de acertos, $43 \%$ e $100 \%$ para leitura e $75 \%, 21 \%$ e $100 \%$ de acertos para a escrita.

Comparando os desempenhos de leitura com escrita em geral, os seis estudantes apresentaram desempenho médio na intervenção aplicada pelos professores de sala de aula de $86 \%$ de acertos e $78 \%$ com a intervenção aplicada pelo professor de educação especial para leitura, já para escrita os desempenhos médios foram $83 \%$ e $65 \%$ de acertos após o ensino. Em uma análise individual, com exceção de A4 que leu e escreveu todas as 14 palavras corretamente, os demais apresentaram maior desempenho para as tarefas de leitura, quando comparados com escrita, o que corrobora os achados de estudos anteriores aplicados com outras populações e diferentes aplicadores (Rose, Souza, \& Hanna, 1996; Souza \& Rose, 2006; Melchiori, Souza, \& Rose, 2000; Reis, Souza, \& Rose, 2009).

Esses dados demonstram, ainda, indícios de que, quanto maior o número de palavras treinadas, maior a probabilidade de recombinação silábica, o que propicia a leitura de um número maior de palavras (Rose et al., 1996; Souza \& Rose, 2006; Melchiori et al., 2000; Reis et al., 2009), em termos de aprendizagem cumulativa com todas as intervenções aplicadas isoladamente, como no caso da análise dos dados obtidos com a aplicação da segunda avaliação geral (AG2). Essa avaliação foi aplicada após o ensino de sete palavras com duas sílabas e antes do ensino de palavras com três sílabas. Após o ensino das palavras com duas sílabas, os estudantes começaram a ler e escrever as palavras que seriam ensinadas posteriormente. Para as tarefas $B C$ e $C B, A 1$ apresentou $100 \%$ de acertos para as palavras que seriam ensinadas apenas no Ensino 2, na $A G 2$, enquanto $A 2$ e $A 3$ demonstraram os mesmos avanços, passaram de $25 \%$ de acertos na $A G 1$, para $50 \%$ para CB e $75 \%$ de acertos para BC, na AG2. Para a tarefa de nomeação de palavra impressa (relação CD), A4 leu 14\% das palavras do Ensino 1 na AG1 e na AG2 (após o Ensino 1) leu $71 \%$ das palavras que seriam ensinadas posterior- 
mente. O mesmo ocorreu para escrita, A1 não escreveu nenhuma palavra correta do Ensino 2, no pré-teste (AG1). Após o Ensino 1, escreveu (sob controle de ditado manuscrito e por composição) corretamente $50 \%$ das palavras que seriam ensinadas no Ensino 2, na AG2. A4, por sua vez, que na AG1 não escreveu nenhuma palavra do Ensino 2, na AG2 demonstrou $25 \%$ de acertos no ditado por composição e $50 \%$ no manuscrito, sem ensino direto destas palavras. E, após, o ensino direto de tais palavras, na AG3, demonstrou $100 \%$ de acertos para os dois ditados.

Esse fenômeno parece ocorrer independentemente do professor responsável pela aplicação da intervenção, do contexto de aplicação e do tipo de atividade aplicada (ensino da palavra isolada, como proposto pelo professor de educação especial ou ensino no contexto da frase, como proposto pelo professor de sala).

Ainda que os resultados do presente estudo não permitam aferir qual a melhor estrutura de ensino (formato proposto em cada intervenção: ensino de uma palavra por vez na intervenção aplicada pelo PEE e ensino a partir de frases na intervenção aplicada pelo PSA), os desempenhos alcançados pelos estudantes nos dois experimentos foram maiores na AG3, quando comparados à AG1 e progrediram de acordo com seus ritmos individuais de aprendizagem, de acordo com a literatura as frases parecem favorecer o ensino de leitura, por fornecerem o contexto para a aprendizagem da palavra isolada (Felippe, Rocca, Postali, \& Domeniconi, 2011). Desse modo, acredita-se que seja necessária a investigação mais acurada das estratégias pedagógicas utilizadas, em relação ao ensino da palavra isolada ou da palavra no contexto de frases, em busca de estratégias de ensino que favoreçam uma aquisição mais rápida desse repertório.

O estudo evidencia a forte validade interna, sobretudo em relação à descrição e detalhamento do procedimento de ensino e certa limitação no que concerne ao numero amostral, para analisar a validade externa. Sugere-se que estudos posteriores ampliem o número de participantes, com o propósito de aferir tal validade.

A estruturação da intervenção de ensino, com tarefas padronizadas, o emprego de replicações sistemáticas de avaliações e feedbacks imediatos para cada desempenho, favoreceu o acompanhamento, em detalhes, dos desempenhos (em termos de progressos) de cada estudante, o que possibilitou a aprendizagem das habilidades básicas de leitura e escrita com estudantes com DI e TEA e, ademais, permitiu a confirmação da hipótese de que a programação de ensino quando delineada, de modo detalhado e controlado, por meio de um delineamento experimental que garanta a avaliação das variáveis dependentes é suficiente para garantir o ensino de habilidades básicas de leitura e escrita (Benitez \& Domeniconi, 2016).

A situação estruturada arranjada pelo psicólogo escolar, em conjunto com as estratégias de ensino decorrentes da situação natural dos professores, como a leitura oral de um texto (atividade que todos os professores de sala de aula realizavam diariamente com todos os seus estudantes), somada ao uso extensivo de jogos informatizados que visavam à alfabetização pelo professor de educação especial, resultou como uma situação promissora para a operacionalização de uma consultoria colaborativa, tendo 
o psicólogo escolar como agente consultor, o que replica os achados de Silva e Mendes (2012), no sentido de identificar mais uma perspectiva de trabalho para o psicólogo escolar. Além de atuar como agente que contribui na prevenção e redução de problemas de comportamentos na escola (Silva \& Mendes, 2012), os dados do presente estudo direcionam uma atuação destinada ao planejamento e à implementação de uma intervenção de ensino que promova a aprendizagem de habilidades acadêmicas básicas, como leitura e escrita, em colaboração com os professores envolvidos com os estudantes com DI e TEA.

A forma de atuação do PEE possibilita ainda outra interpretação de consultoria. Ao retirar o estudante da sala de aula para aplicar suas respectivas atividades de leitura e escrita, devido à demanda identificada pelo professor da sala comum, o professor de educação especial pode prestar uma assessoria ao outro professor, no processo de ensino de leitura e escrita (Araújo \& Almeida, 2014; Rosin-Pinola \& Del Prette, 2014). Estudos posteriores poderiam avaliar os dados dos dois professores atuando em conjunto, com o mesmo objetivo, a fim de concretizar a parceria colaborativa entre eles, com a consultoria do psicólogo escolar na elaboração e proposição da intervenção de ensino acadêmica.

A inclusão escolar dos seis estudantes apresentou diferenças importantes quanto à participação das atividades na sala de aula comum. A1, A2, A4 frequentavam escolas públicas. Tal município conta com a participação de professores colaborativos, porém estes professores atendem diferentes estudantes ao longo da semana, o que significa que muitas vezes, os estudantes, sobretudo aqueles com TEA não frequentam a escola comum diariamente, por não terem um professor que os acompanhasse nas diferentes atividades durante todos os dias da semana. A1 recebia tal atendimento três vezes por semana e, portanto, frequentava a escola nestes três dias, A2 e A4 uma vez por semana, porém frequentavam a escola diariamente. A3 e A6 estavam matriculados em escolas estaduais, as quais não apresentavam esse modelo de ensino colaborativo e frequentavam as aulas diariamente. E A5 estava matriculada em uma escola particular que também não contava com o modelo de ensino colaborativo, porém contava com a presença de uma estagiária que a acompanhava diariamente.

No que concerne ao serviço de atendimento educacional especializado (AEE); $A 1$, A2, A4 e A6 realizavam tais atividades no contraturno escolar, os demais não recebiam tal atendimento. Em relação ao planejamento das atividades de leitura e escrita com cada um dos estudantes, nenhum deles era exposto diretamente a tais atividades de modo estruturado, com acompanhamento individualizado, apenas atividades que visavam o desenvolvimento do domínio motor (coordenação motora fina e grossa), domínio social, domínio de comunicação em sala de aula (principalmente, com A5) e artístico (como colorir, recortar, colar, dentre outros). As atividades não apresentavam uma programação de ensino sequenciada e critérios de aprendizagem para mudança da dificuldade. A programação de ensino proposta replicou o modelo de ausência de critérios de aprendizagem, para aproximar ainda 
mais da realidade a que estavam expostos e, mesmo com a ausência de critérios, os estudantes demonstraram maior domínio da leitura e escrita nas avaliações finais. Todavia, a presença extensiva das avaliações permitiu aferir a aprendizagem de cada estudante. Estudos futuros podem buscar mais evidências a respeito da necessidade de critérios ou não de ensino.

Uma parte importante da consultoria colaborativa se refere ao processo inicial do consultor (no caso, o psicólogo escolar) identificar a realidade educacional e dela partir para uma proposição de trabalho igualitário com os professores envolvidos, de modo que a colaboração ocorra pelas duas vias, tanto pelo consultor, como pelo consultado (Mendes et al., 2011). O trabalho colaborativo entre os professores de educação especial e de sala comum ainda se mostrou como um grande desafio nas escolas que apresentavam esse modelo, visto que em termos práticos o planejamento das atividades não era compartilhado entre eles e o horário de planejamento, muitas vezes, não era suficiente para atender essa demanda e, além disso, nem sempre era possível reunir todos os professores envolvidos com o caso conjuntamente. A garantia do espaço e horário de discussão parece estar assegurada, porém a presença de todos os professores envolvidos com o caso, ainda parece uma situação desafiadora (Rodrigues et al., 2012).

Portanto, se o objetivo da educação especial na escola comum é criar condições para promover a autonomia, independência e a aprendizagem acadêmica dos estudantes público-alvo da educação especial (com destaque para DI e TEA), sem qualquer discriminação, é necessário, primeiramente, garantir o professor de educação especial, atuando no modelo colaborativo, em conjunto com o professor da sala de aula comum, além de operacionalizar e sistematizar atividades de leitura e escrita a serem aplicadas tanto pelo professor da sala de aula comum, com todos os estudantes, como também com o professor de educação especial. É nesse contexto que a consultoria colaborativa de outros profissionais adicionais pode contribuir na promoção do ensino e aprendizagem para todas as crianças, em especial, o psicólogo escolar (Araújo \& Almeida, 2014; Silva \& Mendes, 2012).

O psicólogo escolar, como consultor colaborativo, pode contribuir na estruturação de uma intervenção de ensino de leitura e escrita em conjunto com os professores (da sala de aula comum e da educação especial). Os dados produzidos, portanto, afirmam que os professores são capazes de aplicar uma intervenção estruturada que promova o ensino destas habilidades acadêmicas básicas para estudantes com DI e TEA matriculados na escola regular, de modo a contrastar os dados do Censo de 2010 e como uma possibilidade de reverter à participação mínima desses estudantes nas provas de larga escala, com a Prova Brasil (Meletti \& Bueno, 2011; Silva \& Meletti, 2014).

A atuação do psicólogo escolar como consultor colaborativo pode ocorrer com o foco da prevenção e estender para outros segmentos sociais, como a família e a comunidade, a fim de buscar reflexões conjuntas entre todos os envolvidos, com o propósito de criar práticas concretas que promovam o ensino da leitura e da escrita para estudantes com DI e TEA matriculados nas escolas comuns. 


\section{Referências}

Araújo, S. L. S., \& Almeida, M. A. (2014). Contribuições da consultoria colaborativa para a inclusão de pessoas com deficiência intelectual. Revista de Educação Especial, 27(49), 341-351.

Associação Americana de Psiquiatria. APA. (2013). Manual diagnóstico e estatístico de transtornos mentais - texto revisado. (5a. ed.). Porto Alegre, RS: Artes Médicas.

Benitez, P., \& Domeniconi, C. (2014). Capacitação de agentes educacionais: proposta de desenvolvimento de estratégias inclusivas. Revista Brasileira de Educação Especial, 30(3), 371-386.

Benitez, P., \& Domeniconi, C. (2016). Use of a computerized reading and writing teaching program for families of students with intellectual disabilities. The Psychological Record, 66(1), 127-138.

Brasil, 2013. Lei $n^{\circ} 12.796$ de 2013 que altera a Lei 9.394 de 1996, que estabelece as diretrizes e bases da educação nacional. Disponível em: http://www.planalto.gov. br/ccivil_03/_Ato2011-2014/2013/Lei/L12796.htm\#art1 Acesso em: 27 fev. 2015.

Censo do Instituto Brasileiro de Geografia e Estatística - IBGE. (2010). Pessoas com deficiência alfabetizadas e não alfabetizadas no estado de São Paulo. Recuperado em 2 janeiro, 2015, de http://www.pessoacomdeficiencia.sp.gov.br/ultimas-noticias/dados-do-censo-ibge-de-2010.

Fein, D., Barton, M., Eigsti, I. M., Kelley, E., Naigles, L., Schultz R. T., Stevens, M., Helt, M., Orinstein, A., Rosenthal, M., Troyb, E., \& Tyson, K. (2013). Optimal outcome in individuals with a history of autism. J. Child Psychol. Psychiatry, 54(2), 195-205.

Felippe, L., Rocca, J. Z., Postali, L. M. M., \& Domeniconi, C. (2011). Ensino de palavras retiradas de livros de histórias infantis por meio de procedimento por exclusão. Temas em Psicologia, 19(2), 563-578.

Gena, A. (2006). The effects of prompting and social reinforcement on establishing social interactions with peers during the inclusion of four children with autism in preschool. International Journal of Psychology, 41(6), 541-554.

Leblanc, M. P., Ricciardi, J. N., \& Luiselli, J. K. (2005). Improving discrete trial instruction by paraprofessional staff through an abbreviated performance feedback intervention. Education and Treatment of Children, 28(1), 76-82.

Melchiori, L. E., Souza, D. G. de, \& Rose, J. C. de (2000). Reading, equivalence and recombination of units: a replication with students with different learning histories. Journal of Applied Behavior Analysis, 33(1), 97-100.

Meletti, S. M. F., \& Bueno, J. G. S. (2011). Os indicadores educacionais como meio de avaliação das políticas de educação especial no Brasil - 2000/2009. In J. G. S. Bueno. (Org.). Educação especial brasileira: questões conceituais e de atualidade (p. 159-182). São Paulo: Educ. 
Mendes, E. G., Almeida, M. A., \& Toyoda, C. Y. (2011). Inclusão escolar pela via da colaboração entre educação especial e educação regular. Educar em Revista, 41(1), 81-93.

Reis, T., Souza, D. G. de, \& Rose, J. C. de (2009). Avaliação de um programa para o ensino de leitura e escrita. Estudos Avaliação Educacional, 20, 425-449.

Rodrigues, I. B., Moreira, L. E. V., \& Lerner, R. (2012). Análise institucional do discurso de professores de alunos diagnosticados como autistas em inclusão escolar. Psicologia: Teoria e Prática, 14(1), 70-83.

Rose, J. C. de, Souza, D. G. de, \& Hanna, E. S. (1996). Teaching reading and spelling: exclusion and stimulus equivalence. Journal of Applied Behavior Analysis, 29(4), 451-469.

Rosin-Pinola, A. R., \& Del Prette, Z. A. P. (2014). Inclusão escolar, formação de professores e a assessoria baseada em habilidades sociais educativas. Revista Brasileira de Educação Especial, 20(3), 341-356.

Sanches, A. C. G., \& Oliveira, M. A. F. (2011). Educação inclusiva e estudantes com transtorno mental: um desafio interdisciplinar. Psicologia: Teoria e Pesquisa, 27(4), 411-418.

Silva, M. C. V., \& Meletti, S. M. F. (2014). Estudantes com necessidades educacionais especiais nas avaliações em larga escala: prova Brasil e ENEM. Revista Brasileira de Educação Especial, 20(1), 53-68.

Silva, A. M., \& Mendes, E. G. (2012). Psicologia e inclusão escolar: novas possibilidades de intervir preventivamente sobre problemas comportamentais. Revista Brasileira de Educação Especial, 18(1), 53-70.

Souza, D. G. de, \& Rose, J. C. de (2006). Desenvolvendo programas individualizados para o ensino de leitura. Acta Comportamentalia, 14(1), 77-114.

Vilaronga, C. A. R., \& Mendes, E. G. (2014). Ensino colaborativo para o apoio à inclusão escolar: práticas colaborativas entre os professores. Revista Brasileira de Educação, 95(239), 139-151.

Zanon, R. B., Backes, B., \& Bosa, C. A. (2014). Identificação dos primeiros sintomas do autismo pelos pais. Psicologia: Teoria e Pesquisa, 30(1), 25-33.

Webb, R., Greco, V., Sloper, P., \& Beecham, J. (2008). Key workers and school: meeting the needs of children and young people with disabilities. European Journal of Special Needs Educational, 23(3), 189-205.

Wechsler, D., \& Figueiredo, V. L. M. (2002). WISC-III: Escala de Inteligência Wechsler para crianças. Adaptação brasileira da $3^{a}$ edição. São Paulo: Casa do Psicólogo.

Submissão: 7.1.2015

Aceitação: 14.9 .2016 